EDUR • Educação em Revista. 2020; 36:e225107

DOI: http://dx.doi.org/10.1590/0102-4698225107

(9) (1) https://creativecommons.org/licenses/by/4.0/

ARTícULO

\title{
DISTRIBUCIÓN DE BECAS Y VACANTES EN ESCUELAS DE UNIVERSIDADES NACIONALES EN ARGENTINA: PERCEPCIONES DE JUSTICIA DE ESTUDIANTES Y DOCENTES
}

PEDRO NÚÑEZ ${ }^{1}$

ORCID: https://orcid.org/0000-0003-2187-253X

EMILIA DI PIERO 2

ORCID: http://orcid.org/0000-0002-1500-7542

\begin{abstract}
RESUMEN: En toda sociedad existen bienes valiosos que es necesario distribuir, para lo cual es preciso contar con un principio que legitime cómo repartirlos. En un contexto latinoamericano que combina expansión del nivel medio y nuevas estrategias de distinción, nos preguntamos por las nociones de justicia a las que apelan estudiantes y docentes de establecimientos educativos dependientes de universidades nacionales en Argentina: escuelas de la Universidad Nacional de La Plata y de la Universidad de Buenos Aires. Exploramos los sentidos en torno a los criterios de justicia distributiva ante bienes escasos: vacantes y becas de estudio. Luego de una breve presentación de las tendencias del sistema educativo y de la discusión sobre el concepto de justicia, analizamos normativas que regulan la admisión. Finalmente, nos detenemos en el caso de las escuelas de la Universidad Nacional de La Plata.
\end{abstract}

Palabras clave: enseñanza secundaria, igualdad de oportunidades educativas, justicia social

\section{DISTRIBUIÇÃO DE BOLSAS E VAGAS EM ESCOLAS DE UNIVERSIDADES NACIONAIS DA ARGENTINA: PERCEPÇÕES DE JUSTIÇA DE ALUNOS E PROFESSORES}

RESUMO: Em toda sociedade existem bens valiosos que devem ser distribuídos, para os quais é necessário ter um princípio que legitime como distribuí-los. Em um contexto latino-americano que combina expansão do nível médio e novas estratégias de distinção, nos perguntamos sobre as noções de justiça por parte de estudantes e professores de estabelecimentos de ensino secundário vinculados a universidades nacionais argentinas: Universidade Nacional de La Plata e da Universidade de Buenos Aires. Exploramos os sentidos em torno dos critérios de justiça

\footnotetext{
${ }^{1}$ Instituto de Investigaciones en Ciencias Sociales de América Latina, Facultad Latinoamericana de Ciencias Sociales, Consejo Nacional de Investigaciones Científicas y Técnicas, Universidad de Buenos Aires. Ciudad Autónoma de Buenos Aires, Argentina. <pnunez@flacso.org.ar>

2 Instituto de Investigaciones en Humanidades y Ciencias Sociales, Consejo Nacional de Investigaciones Científicas y Técnicas/Universidad Nacional de La Plata. La Plata, Buenos Aires, Argentina. <medipiero@gmail.com> Educação em Revista | Belo Horizonte|v.36|e225107|2020
} 
distributiva sobre bens escassos: vagas e bolsas de estudos. Após uma breve apresentação das tendências do sistema educacional e a discussão sobre o conceito de justiça, analisamos as normativas que regulam a admissão. Finalmente, estudamos os casos das escolas da Universidade Nacional de La Plata.

Palavras chave: educação secundária, igualdade de oportunidades educacionais, justiça social

\title{
DISTRIBUTION OF SCHOLARSHIPS AND VACANCIES IN SCHOOLS OF NATIONAL UNIVERSITIES IN ARGENTINA: PERCEPTIONS OF JUSTICE OF STUDENTS AND TEACHERS
}

\begin{abstract}
In every society there is a set of goods considered valuable that must be distributed, for which it is necessary to have a principle that legitimizes the way in which they are distributed. In a Latin American context that combines the expansion of middle-level coverage with the search for new strategies of distinction, we ask ourselves about the notions of justice to which students and teachers of educational establishments dependent on national universities in Argentina appeal: the secondary schools administered by the National University of La Plata and the University of Buenos Aires. In this article, we explore the plot of meanings around the criteria of distributive justice before scarce social goods: vacancies and scholarships. After a brief presentation of the trends of the educational system in the two jurisdictions and the discussion on the concept of justice, in the second section we analyze the regulations of the form of admission to each educational establishments. Finally, we focus on the particular case of the dependent schools of the National University of La Plata.
\end{abstract}

Keywords: secondary school, equal educational opportunities, social justice

\section{INTRODUCCIÓN}

La Argentina, al igual que otros países de la región, logró en la última década un progresivo incremento de las tasas de escolarización en el nivel medio ${ }^{3}$. De manera concomitante, persisten desigualdades en la calidad del tiempo escolar, los niveles salariales docentes y las políticas públicas implementadas en cada jurisdicción, entre otras cuestiones (Kessler, 2014). En este artículo nos proponemos recuperar los debates en torno a las nociones de justicia distributiva para abordar dos aspectos de los procesos educativos que involucran una definición sobre la asignación de posiciones sociales. Para ello consideramos un grupo de establecimientos educativos dependientes de universidades nacionales en Argentina: las escuelas de la Universidad Nacional de La Plata (en adelante, UNLP) y de la Universidad de Buenos Aires (en adelante, UBA). En un contexto que combina la expansión de la cobertura del nivel medio con la búsqueda de nuevas estrategias de distinción nos preguntamos por las percepciones de distintos actores de las escuelas en el momento de activar la distribución de bienes. Específicamente nos detenemos en las percepciones sobre las formas de admisión a estas instituciones y exploramos la trama de sentidos en torno a los criterios de justicia distributiva ante bienes sociales escasos: las vacantes y las becas, así como sobre la razón de elección de las escuelas y las trayectorias a futuro.

Pocas dudas caben que la desigualdad en el sistema educativo en la actualidad adquiere una nueva cartografía que precisa de abordajes novedosos, nuevas perspectivas y formas de

\footnotetext{
${ }^{3}$ Las tasas netas de escolarización secundaria aumentaron de manera considerable en las últimas décadas al pasar del 42,2\% en 1980 a 59,3\% en 1991; 71,5\% en 2001 hasta alcanzar el 85, \% de 2011 (SITEAL). Sin embargo, existen dificultades para sostener la escolaridad dado que las tasas de abandono se incrementan en los tres últimos años pasando de 9,64\% en el secundario básico a 15,83\% en el orientado para el total del país (SITEAL). Desde ya que esta situación muestra diferencias de acuerdo a las regiones del país y por quintiles de ingreso que por una cuestión de espacio no exploraremos aquí.
}

Educação em Revista | Belo Horizonte|v.36|e225107|2020 
analizar sus transformaciones. Si bien una arista insoslayable de los temas de "agenda", que la tendencia a la universalización del nivel medio supuso, fue la relacionada con la desigualdad y el rol que ocupa la escuela en la reproducción y producción de las desigualdades sociales hacia dentro de sus puertas (Mayer \& Núñez, 2017), aún no contamos con una densidad de estudios que logren precisar sus distintas dimensiones o, en palabras de Reygadas (2004), que apelen a enfoques que conjuguen la atención a la distribución de capacidades y recursos, las relaciones e intercambios y las características de las estructuras sociales. Es decir, cómo estudiar el movimiento paradojal de una tendencia a la democratización en el acceso que se combina con la percepción de la desigualdad en la calidad de los bienes educativos -tanto en recursos tangibles como infraestructura o materiales de estudio y en aquellos intangibles vinculados con las formas de circulación de los conocimientos, roles docentes o el tiempo escolar-, las interacciones que tienen lugar y las características de cada institución. En este trabajo sostendremos que la pregunta por la forma de distribución de bienes escasos -vacantes escolares y becas- representa una dimensión esencial para dar cuenta de la dinámica que adquiere la desigualdad educativa.

El artículo está organizado en tres momentos. Al inicio, luego de una breve discusión sobre el concepto de justicia, analizamos las normativas que regulan el ingreso de los estudiantes y describimos los perfiles de las escuelas dependientes de universidades nacionales. En un segundo momento, indagamos en los sentidos que los estudiantes otorgan a sus escuelas, prestando atención a las razones de la elección de establecimientos, para luego focalizarnos en el análisis de sus percepciones sobre la distribución de un bien escaso, en este caso las becas escolares. El corpus que utilizamos es una encuesta aplicada en el marco del Proyecto PICT (ANPCyT/UNIPE) "Escuela media y cultura contemporánea: vínculos generacionales, convivencia y formación ciudadana". Finalmente, nos detenemos en el caso particular de las escuelas dependientes de la Universidad Nacional de La Plata para explorar las percepciones de diferentes actores educativos sobre la regulación del ingreso y los criterios de justicia utilizados al momento de pensar la distribución de vacantes. En este caso los hallazgos forman parte de la tesis doctoral de Emilia Di Piero "Justicia, meritocracia e igualitarismo. Procesos de producción y legitimación de desigualdades en escuelas secundarias universitarias en la ciudad de La Plata".

Desde su conformación, los sistemas educativos debieron resolver cómo distribuir la población demandante de sus servicios. Se trata de un problema central de la administración educativa, no solo debido a la necesidad de infraestructura y financiamiento del personal designado en cada establecimiento sino porque de acuerdo a la dinámica de las políticas puede profundizar, o no, la desigualdad. La forma en que la población objetivo (personas comprendidas entre las edades indicadas para cada nivel) emerge como aspecto central por diversas razones, especialmente porque se relaciona con el tipo de comunidad educativa que se conforma. Efectivamente, tal como lo plantea Walzer (2004) - para pesar de los y las pedagogas- probablemente el contenido del plan de estudios sea menos importante que el ambiente humano dentro del cual debe ser cumplido. La conformación de dicho ambiente -lo que comúnmente llamamos clima escolar-produce formas diferentes de ser joven como consecuencia de la interrelación de tres variables: la composición social de la matrícula -la ubicación de la escuela y los entornos de donde provienen el alumnado-; las configuraciones, mezclas e interacciones que se producen entre ellos en el curso y los climas que se crean en la institución escolar -el trato que reciben- que depende en gran medida de la cultura institucional y de la composición del grupo de profesores (Funes, 2004). Asimismo, como una cuestión aún más importante, la forma en que se distribuye la matrícula puede producir nuevas desigualdades, diferenciando entre quienes acceden a un tipo de establecimientos y quienes sólo anhelan asistir a otros. En definitiva, representa un problema que puede leerse como una distribución desigual de las posibilidades de elección.

En este trabajo abordamos dos aspectos relacionados con la distribución de bienes: por un lado exploramos los sentidos que los estudiantes otorgan a sus escuelas, aspecto que permite dar cuenta de la distribución desigual de las posibilidades de acceder a distintos establecimientos (en un rango que oscila entre quienes enfatizan en el nivel educativo o la 
modalidad y aquellos que sostienen que no tenían otra vacante o que asisten familiares). Esta primera aproximación posibilita indagar en las formas de distribución de bienes escasos como las becas educativas, con la intención de dar cuenta de las lógicas asociadas al esfuerzo y la meritocracia que subyacen al momento de definir qué dar a cada quién. Por otro lado, el estudio de las percepciones sobre la asignación de vacantes en las escuelas dependientes de universidades nacionales se nos presenta como un escenario donde observar los procesos de agregación/asociación y segregación que ocurren en el ámbito educativo. Así como uno de los mandatos que el sistema educativo debe resolver es establecer quiénes podrán acceder a la escolarización, este requerimiento no se comprende de manera acabada si desconocemos que subsume una pregunta de igual o similar fortaleza: ¿con quiénes la compartirán? Ambas cuestiones permiten explorar en la significativa presencia de sentidos asociados a la construcción de igualdad vinculada a la igualdad de oportunidades y al esfuerzo y al mérito como criterios de legitimidad.

En este sentido, la distribución de población en distintas unidades educativas no sólo establece diferencias de acuerdo a la localización o jurisdicción donde se encuentren sino, fundamentalmente, en relación al garante de esa provisión educativa. Vale la pena desagregar este argumento: el sistema educativo está conformado por instituciones de distinto tipo de gestión (estatal y privada -con o sin subsidio estatal, es decir concertadas-), modalidades (bachiller comercial, técnicas, artísticas, entre otras), pero también de acuerdo a si se trata de servicios provistos por los estados provinciales, gestores privados (congregaciones religiosas, establecimientos laicos, empresas, propuestas de educación alternativa) o las universidades nacionales, las cuales -ante el traspaso de los establecimientos de nivel medio a cada provincia en los años 90 en Argentina ${ }^{4}$ - incrementaron su valoración social entre sectores de las clases medias profesionales. Se trata de instituciones prestigiosas y anheladas, lo cual se evidencia en que el número de familias que aspiran a que sus hijos/as transiten su escolarización en estos establecimientos ha ido in crescendo en los últimos años. Aunque de acuerdo a las leyes vigentes, todos los aspirantes de una generación tienen un lugar asegurado en las escuelas secundarias, algunos entre esos lugares son más preciados que otros. En los casos que analizaremos, se disputan las vacantes para ser admitidos/as en este grupo de escuelas en particular porque se trata de instituciones prestigiosas, que portan la excelencia académica como marca distintiva y aseguran una sociabilidad entre iguales en el ámbito estatal.

\section{LAS ESCUELAS DEPENDIENTES DE UNIVERSIDADES: CARACTERÍSTICAS Y FORMAS DE INGRESO}

En el año 2019 Argentina cuenta con 57 universidades nacionales. A su vez, 51 son las escuelas secundarias que de ellas dependen, mientras que la inmensa mayoría de los establecimientos de nivel medio del país responden a los estados provinciales o bien a otros actores privados. Las políticas de admisión que ponen en juego las secundarias universitarias delinean un cuadro variopinto: algunas apelan al orden de llegada, otras se rigen por examen eliminatorio, por mejores promedios en la escuela primaria, cursos de ingreso eliminatorios y nivelatorios, por sorteo público, o bien políticas de acción afirmativa que contemplan un cupo o cuota destinado a aspirantes que han repetido o interrumpido sus trayectorias educativas con anterioridad (Di Piero,

\footnotetext{
4 La Argentina cuenta desde 2006 con una nueva Ley Nacional de Educación (N²6.206) que estableció la obligatoriedad del nivel secundario e intentó dotar de mayor homogeneidad a un sistema educativo que había atravesado en los años noventa una reforma virulenta. Si bien esta normativa reemplaza a la Ley Federal de Educación N²4.195/93 no modificó la Ley de Transferencia ( ${ }^{\circ}$ 24.048/91), que habilitó el traspaso a las provincias sin las partidas presupuestarias necesarias, de aquellas instituciones que estaban aún bajo jurisdicción nacional -el nivel primario había sido ya transferido por la dictadura militar en 1977-. Por lo tanto, si bien existen programas a nivel nacional -que pueden variar de acuerdo a cada administración- la gestión educativa es responsabilidad de cada jurisdicción por lo que existen notorias diferencias en cuanto a su capacidad de llevar adelante políticas en función de las diferencias en sus presupuestos.
}

Educação em Revista | Belo Horizonte|v.36|e225107|2020 
2018). En este artículo nos concentraremos en escuelas que presentan dos tipos diferentes de políticas de admisión: sorteo público (UNLP) y el examen eliminatorio (UBA).

En el siguiente mapa podemos ubicar las secundarias universitarias estatales en el país considerando el momento histórico en que fueron creadas:

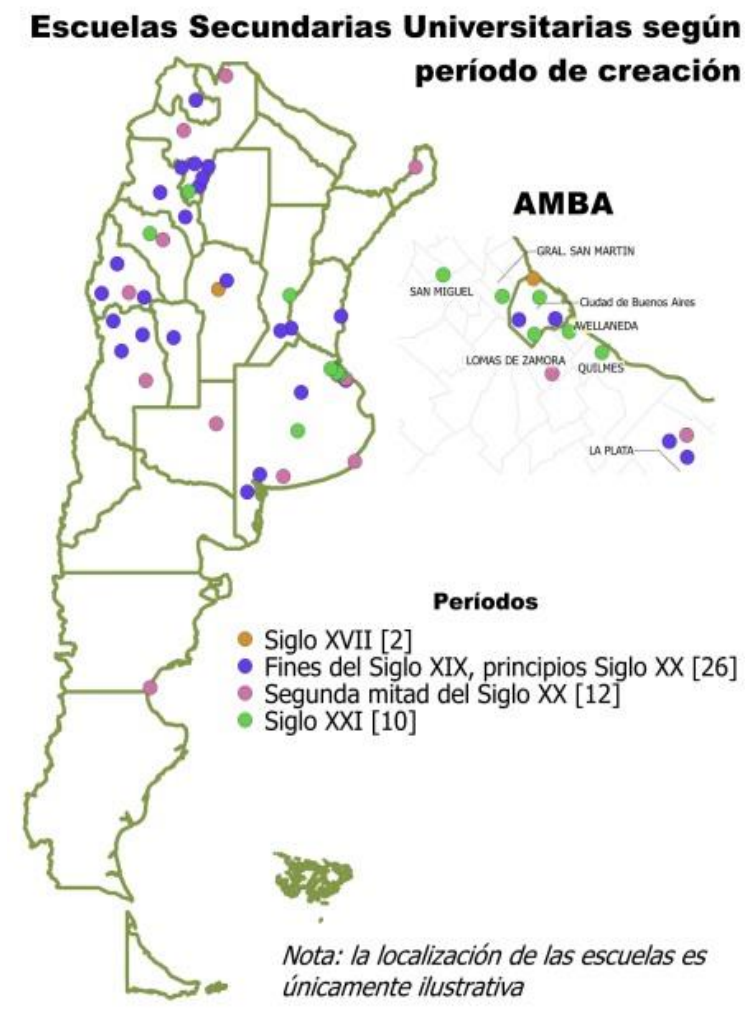

Fuente: Di Piero (2018). Disponible en: http://sedici.unlp.edu.ar/handle/10915/68141

Como señala Di Piero (2017 y 2018), en base a la información recabada sobre los métodos de admisión vigentes en cada una de las secundarias universitarias es posible establecer una tipología compuesta por los siguientes nueve grupos: i) el ingreso meritocrático puro (que a su vez se subdivide en aquellas instituciones que cuentan con exámenes de ingreso y aquellas que habilitan las vacantes a quienes poseen los mejores promedios en su escolarización primaria); ii) el ingreso por sorteo; iii) aquellas que cuentan con cursos de ingreso no eliminatorios; iv) las que cuentan con cursos de ingreso eliminatorios; v) las que priorizan el ingreso de los estudiantes provenientes de las primarias universitarias con las cuales articulan la escolarización; vi) las que presentan políticas de admisión que contemplan la prioridad de determinados grupos focalizados de la población; vii) las que contemplan la existencia de lazos sanguíneos (hijos/as de docentes, hermanos/as que ya transitan la escolaridad allí); viii) las que contemplan la cercanía al radio de la vivienda y ix) las que incluyen también el pago de una inscripción. Dado que varios de los establecimientos combinan y superponen diversos mecanismos de ingreso, es posible ubicarlos en distintos grupos a la vez. La mayoría de las escuelas secundarias universitarias cuentan con mecanismos de admisión ligados a criterios meritocráticos (Di Piero, 2017 y 2018).

En el caso de la UNLP, escogimos dos escuelas de las cuatro secundarias de pregrado asentadas en la ciudad considerando que presentan orientaciones diferenciadas: un bachillerato común (al que llamaremos Escuela 1) y un bachillerato con especialidad artística (al que llamaremos Escuela 2). Asimismo, la escuela artística cuenta con la particularidad de ser la última de las tres secundarias universitarias de la ciudad en adoptar el sorteo como único método de acceso. Hasta el año 2015 el sorteo convivía con una "Evaluación de competencias de los lenguajes artísticos" 
para el ingreso en $1^{\circ}$ y $4^{\circ}$ año de la secundaria, tensionando de ese modo dos criterios de justicia diferentes: el azar y el mérito. Asimismo, esta institución presenta una particularidad en relación con el ingreso, dado que en paralelo a $5^{\circ}$ y $6^{\circ}$ año de la EPB los/as aspirantes pueden cursar un ciclo de dos años denominado Ciclo Básico de Formación Estética en el cual se espera que los estudiantes aprendan los elementos básicos de la Música o las Artes Visuales, de acuerdo a la especialidad que elijan 5 .

Se trata de instituciones tradicionales que históricamente atendieron a sectores con nivel educativo alto reclutados mediante examen de ingreso eliminatorio y que a mediados de los años 80, en el contexto de la denominada transición democrática en Argentina tras la última dictadura militar, modificaron -de modo parcial o absoluto según el caso- su método de ingreso hacia el sorteo, adaptándose a la configuración que el mandato democratizador adquiría en ese momento, es decir, al acceso directo e irrestricto.

En el caso de la escuela ubicada en la Ciudad de Buenos, es una institución creada hacia fines del siglo XIX con el objetivo de consolidar cuerpos de profesionales con orientación contable de manera experimental, es decir, con una metodología diferente al resto de las escuelas. Es una de las cinco instituciones dependientes de la Secretaría de Educación Media del Rectorado de la Universidad, la cual se creó con el fin de asesorar al Rector sobre todos los asuntos relativos a las cinco escuelas secundarias que dependen de ella ${ }^{6}$. Tiene un plan de estudios de cinco años y la opción de cursar allí sexto año con materias equivalentes a las del Ciclo Básico Común de la Universidad de Buenos Aires. Se trata de una institución que mantiene el examen de ingreso, donde los/as aspirantes deben rendir pruebas de lengua, matemática, historia y geografía a lo largo de un curso de ingreso que posee una extensión de 37 semanas y establece la selección final de acuerdo al orden de mérito (Núñez \& Otero, 2018). Este examen meritocrático se combina con otra forma de distribución una vez que se ha accedido a la institución. Efectivamente, el establecimiento cuenta con tres turnos: mañana, tarde y vespertino, a los cuales los ingresantes acceden mediante un sorteo. Si bien el título que otorga es el de perito mercantil, en los últimos años la gestión de diferentes rectores le imprimió un perfil más humanista y de reflexión crítica en la formación ciudadana que desdibujó la importancia de la modalidad en la elección de la escuela, al tiempo que cobraron relevancia aspectos como la formación crítica, la sociabilidad y la heterogeneidad de estilos juveniles; aspectos valorados por los estudiantes entrevistados ${ }^{7}$.

Una de las características de esta institución -que comparte con otra también emblemática de la UBA- es el fuerte peso institucional y político de los sujetos que la componen: además de las autoridades, también se incluye la Asociación de ex Alumnos, los gremios docentes y las agrupaciones estudiantiles. Estas presencias convierten a la escuela es un espacio diverso en términos de sujetos, pero también sumamente complejo y conflictivo en términos de luchas de intereses en pugna. Estas características son similares a instituciones emblemáticas existentes en otras provincias como en el caso de escuelas dependientes de la Universidad de Buenos Aires, la Universidad Nacional de Rosario o las que forman parte de la Universidad de La Plata, tal como señalaron estudios recientes (Méndez, 2013; Núñez y Litichever, 2015; Otero, 2018).

\footnotetext{
${ }^{5}$ Fuente: página oficial de la Escuela 2. Disponible en: http://www.bba.unlp.edu.ar/ingreso. Consultado el día: $11 / 09 / 2018$

${ }^{6}$ Estas escuelas fueron creadas con fines propedéuticos. Los cuatro establecimientos dependientes en su totalidad son: un colegio con orientación en Bachiller, una escuela Comercial, una escuela Agropecuaria y, recientemente inaugurada, una escuela Técnica. Y posee potestad académica sobre un instituto de idiomas de gestión privada. Todas ellas están ubicadas en diferentes barrios de la Ciudad de Buenos Aires y asisten estudiantes de variados sectores sociales.

7 Para aprobar el año lectivo los estudiantes pueden tener dos materias previas (cuando en el resto de las escuelas porteñas, que dependen del Gobierno de la Ciudad y no de la Universidad, pasan de año adeudando tres materias). En caso de deber entre dos y cuatro materias pueden cursar el año siguiente en condición de libres, es decir, asisten a clase obligatoriamente, pero a fin de año deben aprobar todas las materias del año que cursaron más las asignaturas previas.
} 


\section{NUEVOS PRISMAS PARA ESTUDIAR LA DISTRIBUCIÓN DE BIENES EDUCATIVOS}

Unas páginas más arriba señalamos que la distribución de la población en unidades educativas es una de las funciones principales del sistema educativo y que este conjunto de procedimientos permite observar, en un nivel micro, la percepción de los sujetos sobre la desigualdad. Entendemos que, así como la educación es una esfera que contribuye a crear una percepción sobre la igualdad de oportunidades, el incumplimiento de esta premisa posee repercusiones a nivel micro, es decir, en las percepciones que tienen los sujetos acerca del modo en que consideran que fueron tratados a lo largo de su vida, respecto de la evaluación que realicen sobre las posibilidades que tuvieron y de la forma en que dichas oportunidades impactaron en sus biografías. La idea que sostiene que la escuela debe garantizar la igualdad de oportunidades -que continúa vigente en el imaginario de amplios sectores sociales- se convierte en un oxímoron en tanto y en cuanto cada establecimiento delimita parámetros para conformar la comunidad educativa; sus disposiciones explícita o implícitamente funcionan como límites al ingreso, como modos de selección de beneficiarios de bienes escasos así como de delimitar quiénes componen el grupo de "meritorios".

Desde la teoría política, los trabajos clásicos sobre la distribución de bienes enfatizan un aspecto principal de la confianza de los sujetos en la justicia: su imparcialidad. De acuerdo a Martin Jay (1999), la idea de que la justicia es ciega aporta certidumbre a los sujetos desde hace muchos años, probablemente desde la Reforma Protestante. Es, por tanto, su ceguera la que otorga a los individuos la confianza que opera como garantía de que, una vez constituidos en el espacio, público serán tratados con justicia, como iguales ante la ley sin abusos ni desigualdades debido a su posición en la estructura social ${ }^{8}$. Las leyes son la institución política que los seres humanos precisan para ser iguales ya que, si bien -a decir de Arendt- no convierten lo diverso en idéntico e invariable, autorizan la posibilidad de las palabras y de las acciones.

Uno de los trabajos fundamentales para abordar estas cuestiones es el libro Teoría de la Justicia de John Rawls (1993), que desde el momento de su publicación se convirtió en un clásico de la teoría política y despertó pasiones de las más variadas. Como es sabido, Rawls en su trabajo recupera la tradición contractualista y construye su teoría partiendo del supuesto de que los individuos, en el momento de conformar una sociedad, establecen ciertos principios básicos de justicia que no se orientan a la resolución de casos particulares sino que son criterios destinados a aplicarse en relación a lo que denomina la estructura básica de la sociedad, esto es, "el modo en que las instituciones sociales más importantes distribuyen los derechos y deberes fundamentales y determinan la división de las ventajas provenientes de la cooperación política" (Rawls, 1993:23).

Una de las preocupaciones principales de su trabajo es demostrar la necesidad de evitar que las decisiones queden supeditadas a las situaciones particulares. La solución teórica propuesta por Rawls es la utilización de la metáfora del "velo de ignorancia" (la ceguera, podríamos agregar), útil para describir el momento inicial en que los individuos establecen los principios básicos que regirán la sociedad. El autor destaca que ese punto de partida, en el que se discuten los principios sociales sobre los cuales se organizará la sociedad, los individuos -racionales y autointeresados- se encuentran en una situación que les impide conocer su lugar de clase, estatus social, así como desconocer la distribución de capacidades naturales, su inteligencia, fuerza, raza o siquiera la generación a la que pertenecen. Tal como señala Gargarella en un muy difundido estudio sobre las teorías de la justicia, en la posición original presentada por Rawls las partes se orientan a alcanzar un acuerdo capaz de considerar imparcialmente los puntos de vista de todos los participantes ya que "desconocen los rasgos básicos de su biografía” (Gargarella, 1999:40).

\footnotetext{
${ }^{8}$ Cabe recordar que en la tradición jurídica del mundo occidental los actos que los individuos realizan en la esfera privada y que no afectan a terceros no son juzgables sino que su examen queda en el ámbito de su conciencia. Educação em Revista | Belo Horizonte|v.36|e225107|2020
} 
El "desconocer los rasgos básicos de su biografía" es el andamiaje teórico más potente del componente meritocrático en tanto las desigualdades sociales y económicas habrían de ser conformadas de modo tal que a la vez que: a) se espera razonablemente que sean ventajosas para todos; b) se vinculen a empleos y cargos asequibles para todos. Si todos pueden acceder a la misma escuela ya no es injusta ni desigual su opción. Más allá de la concepción del bien adoptada, los individuos pretenden evitar que las instituciones básicas los perjudiquen o discriminen.

En el análisis de la obra de Rawls, Gargarella destaca que el principio de diferencia “implica una superación de una idea de justicia distributiva corriente en sociedades modernas, de acuerdo con la cual lo que cada uno obtiene es justo, si es que los beneficios o posiciones en cuestión eran también asequibles para los demás. En este caso (...) el esquema de justicia no se considera satisfecho con una mera igualdad de oportunidades. Se afirma, en cambio, que las mayores ventajas de los más beneficiados por la lotería natural son justificables sólo si ellas forman parte de un esquema que mejora las expectativas de los miembros menos aventajados de la sociedad" (Gargarella, 1999:39).

En toda sociedad existe un conjunto de bienes que es necesario distribuir, para lo cual es preciso contar con un principio que legitime el modo en que se los reparte. Algunos autores cuestionan la idea de que exista un único principio o axioma que permita explicar las creencias y juicios que se expresan cuando enunciamos que una acción es justa (Walzer, 2004). En Esferas de Justicia Michael Walzer opta por inscribir su investigación en un nivel de análisis diferente a la perspectiva de Rawls. En su estudio, sostiene la existencia de una justicia de naturaleza pluralista: en cada sociedad existen diferentes tipos de bienes sociales cuya distribución requiere en cada caso de criterios particulares de justicia. En tanto existen muchas esferas de la justicia, fundadas en comunidades sociales y prácticas institucionales distintivas, según el autor es necesario reformular el concepto de iguales, a fin de poder pensar en la igualdad compleja como la forma que adquiere la misma en la actualidad. Walzer (2004) procura demostrar que la igualdad es un concepto complejo ya que los valores predominantes en una esfera social no prevalecen necesariamente en otra. Existen, de acuerdo con su perspectiva, diferentes normas de distribución en distintas esferas de actividad: un principio considerado válido en una de ellas no puede ser trasladable a otra donde rigen principios diferentes. Esto implica que en una sociedad en la cual diversas personas tienen éxito en distintas esferas sus relaciones globales pueden exhibir cierto tipo de igualdad (Miller, 1996). Ahora bien, frente a la posibilidad de la utilización de valores predominantes en una esfera como forma de obtener beneficios en otra, Walzer (2004) señala que la misma idea de que distintos bienes deben distribuirse de modo diferente implica un rechazo a la posibilidad de que puedan autorizarse conversiones entre diversas esferas de bienes. No resulta aceptable, por ejemplo, que el dinero, que encuentra sentido en la esfera económica, ocupe un rol significativo en el modo en que se distribuye la mejor educación. Existe cierta tiranía de unos bienes sobre otros cuando un bien domina sobre los demás: la justicia está, según el autor, en que se respeten los principios de cada esfera distributiva?.

Por su parte, en un enfoque que consideramos más próximo a las cuestiones que aquí presentamos, Elster (1998) en Justicia Local parte de la diferenciación entre los términos principio, criterio, mecanismo y procedimiento (1998:77). Con el término "principio", el teórico noruego denomina cualquier concepto general acerca de cómo se designa el beneficio escaso. Con "criterio" refiere a propiedades reales de los individuos (a cada grupo según su necesidad, o la consideración de parientes cercanos). El término "mecanismo" especifica, entretanto, a instancias en que no se requiere un conocimiento individualizado acerca de los receptores potenciales (sorteos, colas, exámenes); por último, "procedimiento" refiere a la versión operacional de un principio (calificaciones, puntaje). En nuestro caso, nos referiremos a principios o nociones de justicia que se activan en torno al mecanismo de admisión o al reparto de becas.

\footnotetext{
${ }^{9}$ Elster critica a Walzer su enfoque normativo: mientras que el primero muestra que los diferentes bienes se distribuyen según principios diferentes, el autor norteamericano se pregunta por cómo deberían ser distribuidos. Educação em Revista | Belo Horizonte|v.36|e225107|2020
} 
De ese modo, el mecanismo de ingreso o reparto de becas por el que se aboga es el "particular" en el cual se tensiona una trama de sentidos en torno a un "universal" como son los principios de justicia distributiva ante un bien social escaso: ya sean las becas, que colaborarían con la posibilidad de escolarización, o las vacantes, codiciadas en tanto se supone garantizarían la pertenencia a un grupo social prestigioso, una sociabilidad entre iguales y la posesión de un estatus. Es más, sostendremos que en un escenario de dispersión y fragmentación, la posibilidad de asistir a una institución dependiente de una universidad nacional dota de un prestigio a quienes lo logran que funciona a modo de atributo diferenciador. Efectivamente, tal como enfatizan quienes describieron las transformaciones recientes en la estructura social argentina, en un contexto de incremento de los niveles de estudios de la población, adquieren más importancia los factores complementarios a los niveles de estudio como las instituciones proveedoras de credenciales o atributos como el capital social, la habilitad para manejarse dentro de ciertos contextos socioculturales o la apariencia personal. (Benza, 2016). La asistencia a una escuela dependiente de una universidad nacional no sólo establece una diferencia en cuanto a la institución proveedora de la credencial sino, fundamentalmente, enviste a quienes allí estudian de los saberes legitimados para moverse en ciertos ámbitos de sociabilidad que los acompañarán en diferentes momentos de su trayectoria futura.

\section{SENTIDOS SOBRE LA ESCUELA: RAZONES DE ELECCIÓN DE LA ESCUELA Y CRITERIOS DE DISTRIBUCIÓN DE BECAS EDUCATIVAS}

En este apartado presentaremos brevemente los resultados del trabajo de campo del Proyecto PICT (ANPCyT/UNIPE) "Escuela media y cultura contemporánea: vínculos generacionales, convivencia y formación ciudadana", al que hicimos referencia al inicio, particularmente los resultados de una encuesta autoadministrada realizada a 338 estudiantes de $3^{\circ}$ y $4^{\circ}$ o $4^{\circ}$ y $5^{\circ}$ año, según cada jurisdicción. El trabajo de campo se realizó en nueve escuelas de tres centros urbanos de Argentina: Ciudad de Buenos Aires, tres localidades de la Provincia de Buenos Aires y Comodoro Rivadavia en la Provincia de Chubut. El trabajo de análisis profundizó en el estudio tanto de las diferencias como de las similitudes entre instituciones que se encuentran ubicadas en distintos centros urbanos, establecimientos que, asimismo, cuentan con historias y tradiciones diferentes. En cada centro urbano se seleccionaron escuelas con proyectos que atraviesan la organización escolar (la convivencia, la participación de estudiantes en centros de estudiantes, la educación sexual o intentos de reorganización curricular) y la dinámica de la institución. De esta forma, se incorporó a los análisis una perspectiva que tuvo en cuenta cómo repercute la situación social de cada localización pero también las traducciones y resignificaciones que ello asume en el marco de cada institución en particular (Informe Proyecto PICT, 2018).

En estas jurisdicciones la selección se realizó en base a distintos ejes organizados según los interrogantes del proyecto. En primer término, se consideraron escuelas del nivel secundario ubicadas en espacios segregados socio-espacialmente que redundan en la conformación de una matrícula homogénea en términos socio-económicos y otras ubicadas en zonas céntricas más heterogéneas en términos de orígenes sociales de los y las estudiantes. También en paralelo se consideró incluir en cada ciudad, escuelas con el mismo tipo de especialidad: bachilleratos de formación general, escuelas con orientación en arte y escuelas técnicas. Es decir que partimos de la hipótesis que podríamos hallar diferencias en la experiencia escolar tanto debido a las características del sistema educativo en cada jurisdicción, como debido a las características de la propuesta escolar. Con esta intención incorporamos tres instituciones: una en la ciudad de La Plata y otra en la Ciudad de Buenos Aires, que dependieran de las universidades nacionales locales. En este estudio retomamos los datos para pensar de manera comparativa entre ambas instituciones que además poseen sistemas de ingreso distintos, azar la primera y el curso de ingreso con examen eliminatorio la segunda- y en relación al conjunto de las repuestas del total de las escuelas 
consideradas. Abordamos el estudio de las nociones de justicia vinculando tres aspectos: las razones de la elección de sus escuelas, la decisión de a quién otorgar becas y la percepción sobre las posibilidades de continuar estudiando. Entendemos que se trata de distintas maneras de problematizar la justicia y la desigualdad que nos brindan la oportunidad de reflexionar acerca de los principios que utilizan para distribuir distintos tipos de posiciones sociales: el acceso a una institución educativa, un bien escaso como una beca y posiciones educativas a futuro.

Si bien en la encuesta no consultamos específicamente sobre sus opiniones acerca de la forma de ingreso a las instituciones (recordemos que la mayor parte de las escuelas consideradas no establecen mecanismos indirectos de ningún tipo, sino que se rigen por la distribución de vacantes existente en cada jurisdicción) entendemos que la pregunta sobre las razones de la elección de su escuela funcionan como un primer acercamiento, tanto al sentido que otorgan a su experiencia escolar como a los imaginarios que construyen sobre esa institución y, de manera transitiva, acerca de quienes logran acceder a esos establecimientos.

De acuerdo a lo que puede observarse en el Gráfico $\mathrm{N}^{\circ} 1$ hay dos ítems que se destacan por sobre el resto. La opción más mencionada por quienes estudian en la Escuela CABA es el buen nivel educativo/prestigio, opción que también es señalada por los estudiantes de la Escuela artística en La Plata, aunque en segundo lugar ya que en este caso priorizan la orientación (artística). Si observamos el total de la encuesta estas opciones no superaron el tercio de las respuestas reunidas, por lo que encontramos aquí la construcción de un imaginario, sobre las instituciones a las que asisten, muy diferente de quienes optan por cuestiones como la presencia de amigos o familiares, la recomendación o las posibilidades de conseguir trabajo a futuro. Asimismo, si comparamos ambas instituciones observamos que en el caso de la dependiente de la UBA la modalidad está desdibujada como saber específico, lo que parece priorizar la posibilidad de estudiar en una institución de perfil universitario, por su parte, en la Escuela UNLP esto último es valorado, pero se enfatiza la modalidad artística.

\section{Gráfico N¹: Razones de la elección de la escuela}

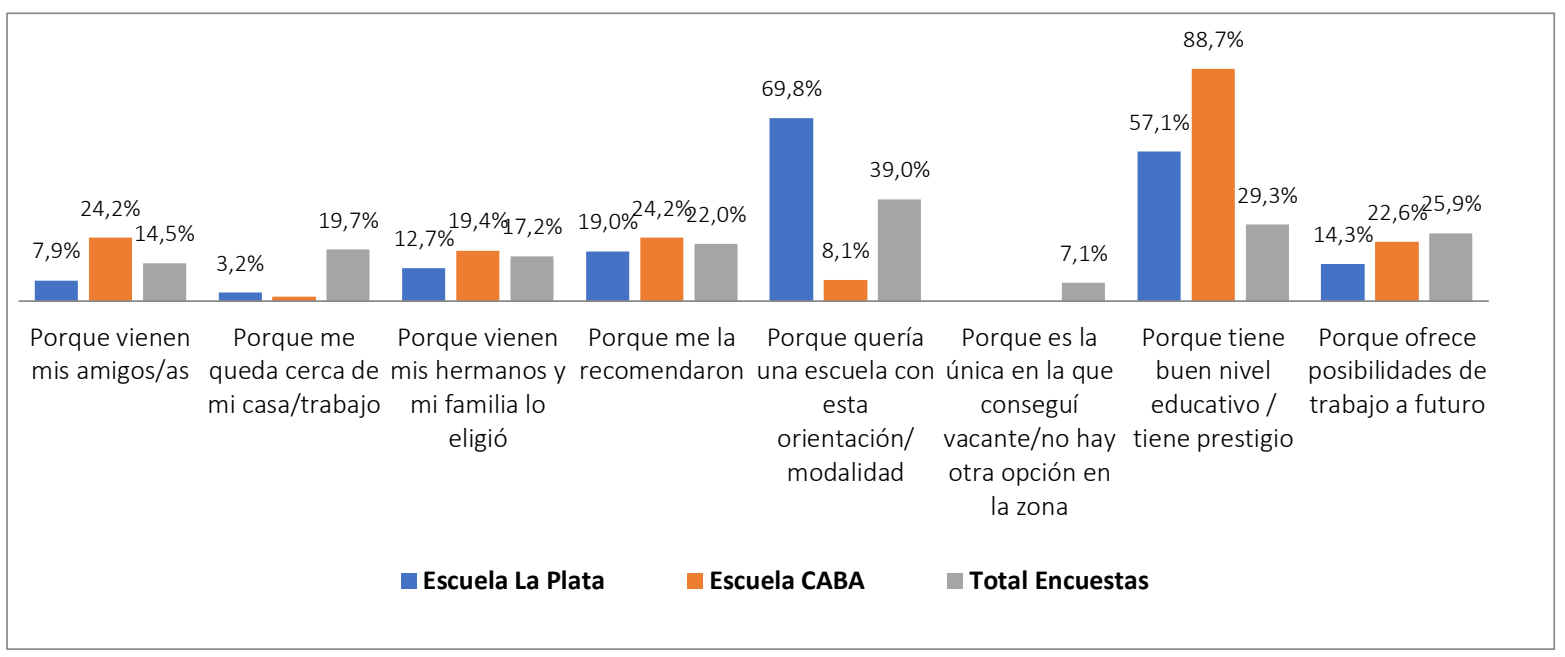

Fuente: Elaboración propia en base a resultados Proyecto PICT (ANPCyT/UNIPE) "Escuela media y cultura contemporánea: vínculos generacionales, convivencia y formación ciudadana”.

La segunda cuestión se vincula a un ejercicio hipotético de distribución de bienes, podríamos caracterizarlo como un caso de justicia local en los términos en que lo propone Elster (1998). Seguimos así un camino iniciado por Kessler (2007) quien fue pionero en la Argentina en introducir en las investigaciones problematizaciones vinculadas a este nivel de análisis de la justicia, a partir del estudio del modo de distribución privilegiado por las personas ante casos hipotéticos y no reales, haciendo hincapié en las culturas políticas nacionales dentro de las que operan. 
Efectivamente, en la encuesta incorporamos el interrogante acerca de qué decisiones tomarían en caso de ser los responsables de distribuir becas educativas. En el Gráfico $\mathrm{N}^{\circ} 2$ presentamos las cuatro respuestas más mencionadas e incorporamos las opiniones de mujeres y varones ya que existen algunas diferencias que queremos resaltar.

\section{Gráfico Nº: Formas de distribución de becas escolares}

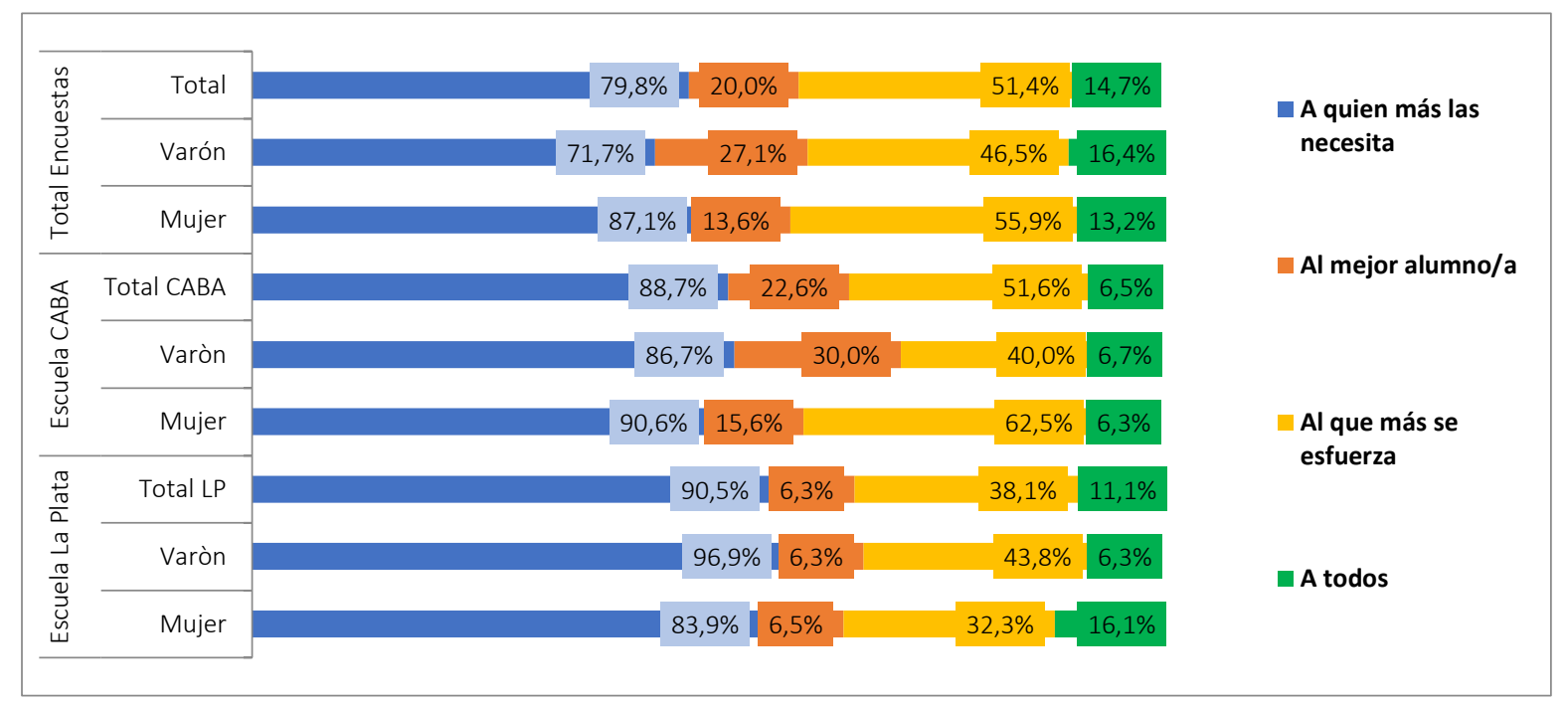

Fuente: Elaboración propia en base a resultados Proyecto PICT (ANPCyT/UNIPE) "Escuela media y cultura contemporánea: vínculos generacionales, convivencia y formación ciudadana"

Lo primero que llama la atención es que no encontramos menciones opuestas a la distribución de bienes como las becas, en tanto no existieron referencias a la opción "a nadie". Pero también cabe señalar que, tal como se observa en el cuadro, los porcentajes que reúne la opción de distribución universal, a todos, si bien es de las cuatro más mencionadas concentra números más bajos en relación a las otras alternativas. Efectivamente, salvo en el total de escuelas y en las estudiantes mujeres de la Escuela artística de la UNLP, los valores son menores al 10\%. Este primer punto nos permite dar cuenta de las dificultades para la construcción de bienes colectivos considerados como derechos de todos.

La opción más señalada fue, tal como es factible observar en el cuadro, la necesidad, como un principio marcadamente más señalado que otros, aunque las diferencias son mayores en las dos instituciones dependientes de las universidades en comparación con el total de encuestas. En este punto no hay diferencias de género significativas. Sin embargo, necesidad es un concepto, si bien operacionalizable, inaprensible. La necesidad puede tener diversas bases de legitimación, la definición acerca de cuál priorizar involucra una dimensión subjetiva. Michael Walzer en Esferas de Justicia lo expresa más claramente: "las personas no sólo tienen necesidades, tienen ideas acerca de sus necesidades, tienen prioridades, grados de necesidad, y tales grados y prioridades se refieren no solamente a su naturaleza humana sino también a su historia y cultura" (Walzer, 2004:77). En el caso que presentamos pareciera existir una correlación entre la definición técnica de los programas sociales que, aunque se planteen como un derecho, poseen características que continúan focalizando en las necesidades de las personas y la percepción de los estudiantes. En sintonía con los modos de asignación de bienes escasos y la organización de las políticas sociales en el país, los jóvenes señalan el principio de necesidad como el principal a considerar, lo que nos habla no sólo de su inscripción dentro de una misma matriz político-cultural sino que parecieran 
apelar a un sustrato común que lo legitima como modo correcto ${ }^{10}$. La asignación es a posteriori, no como derecho de todos sino que la persona que precisa una beca debe demostrar alguno de los atributos exigidos: por ejemplo, no tener ingresos suficientes.

Ahora bien, la segunda alternativa más mencionada fue "al que más se esfuerza", atributo que podríamos caracterizar como parte de los principios definidos por otras propiedades, donde se elige al receptor del bien por la contribución que realizan. Sin embargo, encontramos algunas diferencias entre el conjunto de las instituciones, la Escuela UBA y la Escuela UNLP ya que en los dos primeros casos los porcentajes son similares $(51,4 \%$ y $51,6 \%)$ en el caso platense disminuyen considerablemente para situarse en $38,1 \%$, tratándose además de una opción más elegida por los varones que las mujeres (43,8\% vs. $32,3 \%)$. En sus respuestas observamos que los discursos parecieran reconstruir representaciones sociales vinculadas con una imagen de selección asociada a la medición de su mérito y esfuerzo (Chaves, Fuentes \& Vecino, 2016). El esfuerzo emerge como atributo esencial de certificación de la capacidad de adaptabilidad escolar y la otra cara de la moneda del merecimiento puro en tanto quizá no se trate de quien "naturalmente" descolla en la escuela, pero sí se esfuerza lo suficiente para sostener la escolarización. De allí que predominan miradas que enfatizan que quienes se esfuerzan merecen la escuela (Chaves, Fuentes \& Vecino, 2016). En el caso platense, recordemos que se trata de una institución de modalidad artística, creemos factible señalar que parecieran estar presentes sentidos más vinculados al talento o conocimientos que suelen asociarse con cierta aptitud para el arte que el esfuerzo no alcanzaría a emparejar, por lo que no sería un atributo tan importante como en los otros establecimientos.

Sin embargo, y a pesar de esta disminución del porcentaje de repuestas logrado por esta opción, concentra números significativos. Entendemos que se trata de una distribución basada en un sistema de merecimiento puro, ya que efectivamente el individuo no sabía en el momento en que realizó la acción meritoria -en este caso esforzarse- que eso le generaría el acceso al bien escaso. En esta situación los jóvenes parecieran otorgar al esfuerzo un valor social alto, jerarquizándolo entre otras alternativas posibles. No se nos escapa que gran parte de la promesa educativa se basa en la aprensión al esfuerzo para obtener un reconocimiento a futuro por lo que estaríamos ante una situación en la cual las percepciones juveniles se mimetizan con los valores promovidos por la institución educativa.

Finalmente, cabe destacar que la tercera opción más mencionada (con porcentajes bastante distintos de las dos primeras, y menores pero significativos en relación a la distribución universal pura) es la que podríamos calificar como merecimiento puro, en tanto se le otorga al "mejor". Nuevamente aquí el comportamiento difiere entre el total de instituciones y la Escuela UBA en comparación con la Escuela UNLP que reúne los porcentajes más bajos, aunque similares por género (promedio de 6,3\%). En ambos el total de casos fluctúa en el $20 \%$, pero el número de menciones aumenta en los estudiantes varones, quienes hacen más hincapié en este aspecto $(27,1 \%$ vs. $13,6 \%$ en el total y $30 \%$ vs. $15,6 \%$ en la escuela porteña). Si bien se trata de cuestiones que requieren de una mayor profundización creemos que aquí se pone en juego algo del estilo de los talentos asociados a la modalidad artística, que, tal como señaló Sennett (2003) descree tanto de merecimientos puros como de esfuerzos compensatorios y está más vinculada a la creencia de contar o no con dicha facilidad.

\section{EL CASO DE LAS ESCUELAS DEPENDIENTES DE LA UNIVERSIDAD NACIONAL DE LA PLATA: PERCEPCIONES DE DOCENTES}

A continuación presentaremos cada uno de los agrupamientos emergentes en torno al método de ingreso más justo entre los docentes que, a partir del trabajo de investigación doctoral en dos escuelas de la UNLP (Di Piero, 2016), es posible reconstruir a modo de tipología. Se trata

10 Tal como señala Kessler (2007), la construcción de indicadores en base a las necesidades básicas insatisfechas -la modernista tecnocrática- es una de las formas características de la regulación de la pobreza para América Latina, junto a la caritativa y la asistencial-represiva.

Educação em Revista | Belo Horizonte|v.36|e225107|2020 
de un Bachillerato común y de un Bachillerato con orientación artística. Los agregados que desarrollamos son los cinco siguientes: i) justicia por igualdad de oportunidades; ii) superposición de criterios: azar más mérito; iii) a favor del examen; iv) criterio de ingreso de familiares; v) a favor de los cupos para el ingreso.

En cuanto a la estrategia metodológica adoptada en esta investigación, se trató de un estudio de caso múltiple. Entre los años 2012 y 2016 realizamos numerosas observaciones y ochenta entrevistas: fueron entrevistados en profundidad trece actores "clave" para las instituciones y efectuadas sesenta y siete entrevistas semiestructuradas a docentes seleccionadas/os de modo aleatorio. También fueron revisadas las Actas Taquigráficas del momento en que se discutía la modificación del método de admisión en el Consejo Superior de la UNLP en los años 80 y recuperado un corpus compuesto por seis documentos institucionales que incluyeron información sobre las fichas sociodemográficas de los/as ingresantes y sobre las políticas de admisión vigentes en las cincuenta y una escuelas secundarias dependientes de universidades nacionales existentes en el país.

\section{Justicia por igualdad de oportunidades: el azar como garante de heterogeneidad y democratización}

En el caso del Bachillerato común, dentro del $62 \%$ de docentes que acordaba con la abolición de los exámenes de admisión, un 60\% entendía el sorteo como la metodología más justa para el acceso a bienes sociales escasos y colectivamente deseados como son las vacantes en esta escuela, mientras que el $2 \%$ restante sugería otras opciones (al igual que quienes conforman la zona gris de aquellos que no están "de acuerdo ni en desacuerdo"). Algunos fundamentos de la opción por el sorteo fueron, en palabras de una docente de 30 años Profesora y Licenciada en Geografía:

"El sorteo da la posibilidad a que todos los estudiantes de diversas experiencias y trayectos educativos puedan ser parte de las escuelas de pregrado" (Docente $n^{\circ} 5$, Bachillerato).

En cuanto la Escuela artística, el 57\% de los docentes acordaba con la abolición de los exámenes eliminatorios al momento de la admisión a las escuelas de la UNLP. Para el caso específico de esta escuela, el 46\% prefería el sorteo como método más justo para la admisión sosteniendo que se trataba de un método igualitario y democratizador. Este grupo entendía que se trataba del mejor modo de garantizar la igualdad de oportunidades y discutía con quienes sostienen que las/os aspirantes deben poner en juego sus méritos para conseguir el acceso. Por otra parte, argumentaba que esta concepción a la que ellos se oponen se concentraba, sobre todo, entre los docentes de música. Entre los argumentos a favor del sorteo, una docente de Sociología de 39 años de edad indicaba:

"Porque el examen restringía el ingreso, era un examen elitista" (Docente $\mathrm{n}^{\circ} 2$, Escuela Artística).

$\mathrm{Al}$ igual que en el Bachillerato común, también en la Escuela artística esta postura fue mayoritaria. De este modo, al sentido de lo justo en estas escuelas subyace la representación de una igualdad de oportunidades (Dubet, 2012) garantizada por un sorteo que habilitaría la supervivencia de quienes mejor se adapten una vez dentro de la institución, sosteniendo así, que el sistema es abierto. Aunque muchas veces presentado como ideología progresista que valora la igualdad de oportunidades, en estos dos grupos prima el criterio de la capacidad en el trabajo y la idea de progreso personal a fuerza de talento y autonomía. Esta última característica constituye la singularidad que adquiere en estas escuelas el "ser meritorio": en este grupo de instituciones universitarias el mérito consiste en ser autónomo/a. Sin embargo, esta capacidad de autonomía será demostrada una vez dentro de las escuelas y no mediante tests para ingresar a ellas. 
Siguiendo a Pousadela: "en Argentina, a diferencia de Brasil, la igualdad de oportunidades reclama que alguien se haga cargo de las desigualdades iniciales y desactive sus efectos, aun cuando ello suponga que la institución en cuestión (...) deba internalizar los elevados costos del proceso de nivelación" (2007:107). Es decir que en Argentina el acceso al sistema educativo se presenta mayoritariamente como abierto y desregulado (Tiramonti y Ziegler, 2008; Ziegler, 2011), y los exámenes de admisión son rechazados por considerárselos antidemocráticos. Sin embargo, el hecho de que desde los años 80 no exista selección formal para ingresar no significa que no se produzca selección alguna. Retomando las palabras de otra docente entrevistada:

\section{"El filtro se produce solo, naturalmente" (Docente n² 25, Escuela Artística).}

Es decir que "el filtro" se desarrolla de modos más implícitos y paulatinos: el mérito continúa vigente y se produce una "selección sutil o soft" (Di Piero, 2015).

\section{Superposición de criterios: azar más mérito}

Un segundo grupo de opiniones, que en el Bachillerato representa un 31\% del total de docentes consultadas/os, sostenía que la metodología más justa para ingresar a estas escuelas no es ninguna de las aplicadas hasta el momento: el examen les resulta poco democrático; el sorteo en su forma "pura" les genera desconfianza. A su vez, dentro de este grupo resulta posible reconstruir dos posiciones: por un lado, quienes optan por el curso de ingreso preparatorio general para todos los aspirantes; por otro, quienes sostienen que debe mantenerse la posibilidad del sorteo para un grupo y del examen para otro.

El primer subgrupo proponía el apoyo del sorteo con un curso nivelatorio previo al comienzo de las clases (con carácter no eliminatorio) destinado a quienes fueron sorteados, que actuara a modo de una política de compensación de puntos de partida desiguales:

"Habría que apoyar el sorteo con algo más, como un curso nivelatorio obligatorio en febrero, para que cuando ingresen todos tengan las mismas posibilidades de recibir conocimiento" (Docente $\mathrm{n}^{\circ} 27$, Bachillerato).

Este grupo entendía que existen condicionamientos sociales y culturales relacionados con las socializaciones y escolarizaciones anteriores y que, para que la "carrera" sea justa, el punto de partida tiene que ser justo: se deben corregir las inequidades iniciales. En sintonía con el planteo de Amartya Sen (1996) una buena política igualitaria debe ser sensible a las variaciones en los desempeños: debe concentrar su atención en las capacidades básicas de las personas para convertir esos recursos en libertades en tanto la igualdad en el reparto de los bienes no es suficiente.

Por su parte, el segundo subgrupo engloba a quienes desconfían del sorteo en su "forma pura" en tanto sostienen que, a raíz de la aplicación del azar, acaban siendo excluidos estudiantes que podrían ser "buenos estudiantes" de esta institución, ocupan bancos otros que no saben "aprovechar la oportunidad" y finalmente acaban abandonando. En ese sentido, una docente de informática de 51 años indicaba:

"Está bien dar posibilidad a muchos que no podrían acceder a colegios universitarios. Pero si entraran 25, deberían dejarte 5 vacantes para aquellos alumnos que podrian entrar por examen. Por ejemplo mi bijo, que es muy capaz, se tuvo que conformar con otro colegio secundario porque no entró por sorteo" (Docente n 30, Bachillerato).

La combinación de los criterios del azar y el mérito en la Escuela artística tomaba una forma particular en tanto se encarnaba en un $28 \%$ de los docentes que reivindicaba la existencia de la "Evaluación de competencias de los lenguajes artísticos" vigente hasta el año 2015 para el ingreso en $1^{\circ}$ y $4^{\circ}$ año. Dicha evaluación convivía con el sorteo hasta el ciclo lectivo 2015, a partir 
del cual el ingreso a dicha escuela es exclusivamente mediante el sorteo para el Ciclo Básico de Formación Estética.

Como indica Khan (2011) al referirse al proceso que denomina como "democratización de la desigualdad", las marcas aristocráticas de clase, exclusión y jerarquía son rechazadas y las diferencias se explican, ahora, por las capacidades de las personas. De ese modo, las escuelas participan de manera activa en la fabricación de jerarquías de excelencia.

\section{A favor del examen: el "siglo XX cambalache" y el retorno a la "edad de oro" del mérito}

Otra postura presente entre las/os docentes abogaba por el retorno a cierta "edad de oro" representada por el ingreso a secundarias universitarias mediante examen eliminatorio. Esta concepción, aunque minoritaria, resulta significativa per se y también en tanto se constituye en "el otro" en relación con el cual las anteriormente presentadas se definen. Depositando en el examen el resguardo de la calidad, se configura en este grupo de docentes una visión nostálgica de cierto pasado perdido y superior frente a un presente de siglo XX cambalache en el que la mediocridad se erigiría como soberana.

En consonancia con la noción de mérito propia de la modernidad, en la que por posiciones sociales justas se entendían aquellas que se alcanzan a partir de la competencia entre personas libres de condicionantes ligados al nacimiento o la herencia, entre los docentes que componen este grupo se presupone que la competencia por las vacantes produciría una desigualdad justa basada en el mérito individual. En palabras de una profesora en Ciencias Naturales de 67 años:

"El sorteo es más selectivo. Por examen entran los más capaces, por sorteo entra cualquiera. Ha bajado el nivel. A los chicos no les importa, cuanto menos trabajás, mejor, pasás igual" (Docente $\mathrm{n}^{\circ} 22$; Bachillerato).

Tal como indica Dubet $(2004,2012)$ respecto de algunos supuestos que pueden rastrearse detrás de cierta retórica cargada de nostalgia por el pasado, en la medida en que el mandato que pesa sobre el nivel medio ya no es el de la selección (como mencionamos, en el caso de Argentina, la secundaria es obligatoria y considerada un derecho desde el año 2006), la escuela secundaria no puede desprenderse de los estudiantes que le causan problemas con la misma facilidad con que antes lo hacía. Muchas veces, en los discursos de docentes y demás actores internos y externos a la escuela, los defectos del pasado son olvidados y encubiertos por la añoranza.

Como señala Rawls (1993), el mérito se presenta como una norma de justicia porque aparece como la manera de construir las desigualdades justas en una sociedad que valora la igualdad de los individuos. Ciertamente, si se considera que somos todos iguales y a la vez que toda sociedad clasifica a los individuos, eso no puede ser hecho más que a partir del momento en que individuos libres ponen en juego sus talentos y su trabajo. Siguiendo a Bolívar (2012), el discurso de la equidad ha emergido como una noción más compleja: evocar la "equidad" y no la igualdad supone que determinadas desigualdades, además de inevitables, deben ser tenidas en cuenta.

De este modo, la docente revaloriza el mérito -al que entiende como esfuerzo y trabajo- en tanto justo asignador de posiciones y critica que el sorteo dé lugar a estudiantes a los que "no les importa nada", quienes no saben "aprovechar" la oportunidad que significa ocupar un banco en esta escuela.

En la escuela especializada en arte, entre quienes sostenían el examen de ingreso como mecanismo de admisión más justo resulta interesante recuperar la respuesta de un docente de 63 años con 43 años de antigüedad en la escuela y título de Ingeniero. Al consultarle por el método de admisión, indicaba: 
"Esta era una escuela piloto. Cuando era una escuela como la gente, de excelencia, teníamos 25 alumnos. Depende de cómo lo quieran enfocar, pero la calidad educativa empeoró, y la timba tampoco sirve. Con el sorteo estamos apostando a la timba. Cuando era por examen de ingreso entraban los mejores. Ahora igualaron hacia abajo" (Docente n 34, Escuela artística).

Su mirada nostálgica denunciaba el crepúsculo de la posición de las escuelas universitarias como focos de calidad educativa. El docente contrapone, así, la inclusión y la excelencia como si se tratara de ideales irreconciliables; la inclusión tendría carácter masivo mientras que la excelencia y la calidad serían para unos pocos. Como muestra Perrenoud refiriéndose a la excelencia, si todo el mundo fuera excelente entonces no lo sería nadie: "la excelencia sólo se produce si no está al alcance de todos" (1996:35).

Para concluir, el caso de este grupo que propone el retorno del mérito como criterio se fusiona con una retórica que valora positivamente el esfuerzo y critica las políticas públicas focalizadas sobre sectores desfavorecidos. Así, se pretende poner en valor la idea de merecer ligada a una crítica social más amplia dirigida a los sectores que reciben ayuda sin haberse "esforzado lo suficiente" y se impugna a esos sectores como si todos partieran del mismo punto en el momento de la competencia, priorizando la meritocracia y favoreciendo un proceso de "acumulación de ventajas" (Saraví, 2015:37) según el cual quienes partan de mejor preparación serán quienes ocupen lugares privilegiados. Por otra parte, como afirma Dubet (2012), hay un componente darwiniano en la igualdad meritocrática de oportunidades: se supone que vencedores y vencidos no se deben más que a sí mismos.

\section{La atmósfera cultural familiar como garantía: el criterio de ingreso de familiares a la Escuela artística}

El cuarto grupo que conforma la tipología que presentamos refiere a un sector de docentes en la Escuela 2 que indicaba que la opción de admisión más justa sería aquella que contemplara la posesión de hermanas/os o familiares que fueran alumnos/as o ex alumnos/as de la institución. Esta opción se justificaba mediante distintas vías.

En primer término, algunos entrevistados sostenían que era importante concentrar a los hijos en una misma escuela por una cuestión de organización del tiempo familiar:

"Tener hijos en diferentes escuelas te desajusta la familia, tienen diferentes horarios" (Docente $\mathrm{n}^{\circ}$ 33, Escuela artística).

Por otro lado, desde una visión hereditarista, ciertos docentes indicaban que si uno de los/as hermanos/as había conseguido adaptarse a la propuesta de la escuela, era probable que los/as demás también lo lograran. De ese modo, la escuela se ahorraba un "esfuerzo en vano", en tanto la atmósfera cultural familiar actuaba como garante de una escolaridad exitosa:

"Porque hay habilidades a las que uno va teniendo más predisposición por la familia de la que uno viene. En la Escuela 1 [donde también ejerce la docencia] tengo el caso de la nieta de XX, fundador de la Escuela 2. La nieta quedó afuera por el sorteo, y ella tenía ganas de entrar" (Docente $\mathrm{n}^{\circ} 28$, Escuela artística).

En sintonía con los señalamientos de Bourdieu y Darbel al analizar el público en los museos en Europa, si las ventajas o desventajas pesan sobre las carreras escolares es porque suelen ser acumulativas en las familias: "Los niveles culturales de los miembros de una determinada familia están siempre asociados entre sí. Las posibilidades de continuar los estudios en una ciudad grande o pequeña, de tener acceso a estudios clásicos o modernos dependen de la posición social

11 "Timba" es una expresión coloquial en Argentina que refiere a dejar algo librado a la suerte o el azar. Educação em Revista | Belo Horizonte|v.36|e225107|2020 
de la familia, y la atmósfera cultural de la infancia y el pasado escolar están estrechamente asociados" (2007:108, 109).

Por otra parte, quienes sustentan la continuidad del repertorio cultural familiar y escolar como garantía no evalúan la posibilidad de que en ciertos casos existan rupturas o negociaciones entre ambos repertorios sino que la entienden como una relación necesariamente lineal.

\section{Políticas de acción afirmativa: a favor de los cupos o cuotas para el ingreso a la Escuela} artística

Otro grupo de respuestas encontradas en la Escuela artística exigía que se contemplaran cuotas destinadas a diferentes grupos sociales. Se trata de ofrecer un "trato excepcional" (Fernández Vavrik, 2015), propiciando políticas de acción afirmativa que implican el trato diferencial hacia determinadas categorías sociales. Con la misma lógica que quienes proponían un curso especial para estudiantes con condiciones desfavorables, parten del paradigma de la equidad que entiende que debe tratarse desigualmente a quienes son desiguales, dado que el trato homogéneo mantendrá las diferencias originarias. Quienes optaron por la implementación de cuotas, indicaban:

Las cuotas para diferentes sectores serían porque, si estamos apostando a una mejora de la situación general, tenemos que pensar en todos los sectores sociales (Docente n ${ }^{\circ} 4$, Escuela artística).

Se denomina "acción afirmativa" a un tipo de políticas reparadoras antidiscriminatorias que se focalizan en determinados grupos o categorías sociales. Esas políticas, forjadas y difundidas primeramente en países angloparlantes con tradición multiculturalista, han sido adoptadas gradualmente en América Latina y en Europa durante los últimos 25 años. Han beneficiado a afrodescendientes, pueblos originarios, personas con discapacidad y mujeres, por ejemplo. Sin embargo, su adopción ha sido problemática en Argentina y en Francia, dada su tradición de política escolar y de protección social universalistas (Fernández Vavrik, 2015).

\section{CONSIDERACIONES FINALES}

Este trabajo muestra que, a la par del proceso de expansión y democratización en el acceso al nivel secundario, surgen otras formas de distinción más sutiles que se expresan en la lógica de los merecimientos ante distintas situaciones. Efectivamente, cuando analizamos las opiniones sobre las razones de elección de sus escuelas, la distribución de un bien escaso como una beca o el acceso a las vacantes de las escuelas, hallamos que gran parte de los principios que legitiman esta distribución se sostienen sobre bases meritocráticas. Tal como señala Walzer (2004) una sociedad organizada exclusivamente en la meritocracia y en la igualdad de oportunidades se dividiría en dos clases: aquellos capaces de aprovechar sus oportunidades y quienes no pudieran hacerlo. Esto desdibuja las relaciones de fuerza que tienen lugar, proporcionando explicaciones basadas en la propia falta de esfuerzos de los individuos.

La aplicación de determinado criterio para resolver un diferendo o justificar una decisión -el mérito, la necesidad, cuestiones basadas en el "carácter", la nacionalidad, el género, la condición social de origen, etc.- provoca en las personas intervinientes acuerdos y malestares, en razón de si el principio se ajusta al que consideraban válido como criterio de justicia. Los principios de justicia operan dentro de una matriz político-cultural en la que, si bien las personas suelen apelar a un sustrato común, también pueden existir divergencias y confrontaciones entre las matrices propias del sistema escolar y aquellas consideradas válidas en otros contextos -como el barrio, el mundo laboral, la familia, las grupalidades-. Al hacer hincapié en el estudio de las percepciones de las personas -qué entienden por justicia o injusticia, qué toleran y qué no, cuáles son los criterios 
que consideran válidos para resolver una determinada situación y cuáles para una diferentecontamos con algunas claves interpretativas de la manera de percibir las desigualdades y, a través de ellas, indagar en la socialización política juvenil.

En el caso de la distribución de las vacantes en las secundarias de la UNLP, la opción mayoritaria es por el sorteo público en tanto se lo entiende como garante de la igualdad de oportunidades; por otra parte, al concebir la distribución de las becas en la secundaria de la UBA y la de la UNLP se pondera el criterio de la necesidad, aunque seguido de la opción por quienes más se esfuerzan. En ambos casos (sorteo y opción por quienes más se esfuerzan), existe un sustrato meritocrático en tanto se considera, por un lado, que una vez garantizadas las oportunidades de acceso a las escuelas se pondrán en juego las "capacidades" (Sen, 1996) para sostenerse dentro de las instituciones y, por otro lado, se entiende que las becas deben otorgarse a quienes se esfuercen. En ese sentido, tanto las vacantes como las becas son entendidas como "oportunidades" dadas, que cada quien debe "saber aprovechar". Es decir que es posible captar la lógica de la igualdad de oportunidades como un sustento general para las discusiones en torno a la justicia. Como indica Dubet (2012), el modelo de "igualdad de oportunidades" refiere a la concepción que ofrece a todos la posibilidad de ocupar las mejores posiciones en función de un principio meritocrático. A diferencia de la "igualdad de posiciones", no busca reducir la desigualdad en las posiciones sociales sino anular las discriminaciones que perturbarían la competencia. Las desigualdades serían aceptadas como justas sólo en tanto las posiciones estarían en principio abiertas a todos, y resultaran de una competencia entre individuos a los que se presume iguales en sus puntos de partida. También Duru Bellat y Elise Tenret (2009), al presentar los resultados de una investigación empírica, indican que entre las normas de justicia adquiere protagonismo la meritocracia, en tanto en las sociedades democráticas modernas las desigualdades son aceptadas como justas sólo si son vistas como resultado del esfuerzo, de una competencia abierta, y no de propiedades heredadas.

A partir de las investigaciones aquí presentadas es posible concluir que tanto el otorgamiento de becas a quienes más se esfuerzan como la opción mayoritaria por el sorteo en la distribución de vacantes se sustentan en la noción de la igualdad de oportunidades y resultan, según los actores consultados, los métodos de distribución de bienes escasos más justos en tanto representan una apuesta hacia la igualación de los puntos de partida. La contraparte de que la igualdad en los puntos de partida se encuentre garantizada es, en definitiva, que se legitime el camino a la meritocracia entendida como el modo más justo de asignar posiciones sociales.

\section{REFERENCIAS}

Benza, G. (2016) “La estructura de clases argentina durante la década 2003-2013” en Kessler, G. (comp.) La sociedad argentina hoy, Siglo XXI, Buenos Aires.

Bolívar, A. (2012). Justicia social y equidad escolar. Una revisión actual. Revista Internacional de Educación para la Justicia Social (RIEJS), 1(1), 9-45.

Chaves, M.; Fuentes, S. \& Vecino, L. (2016) Experiencias juveniles de la desigualdad. Fronteras y merecimientos en sectores populares, medios y altos, Buenos Aires: Grupo Editor Universitario.

Di Piero, E. (2015). “¿Mérito y azar? Nociones de justicia distributiva y selección soft: el caso de una escuela secundaria tradicional frente al mandato inclusor”. Revista Propuesta Educativa, n.43, año 24, jun, $\quad$ vol $\quad 1, \quad$ p.152- 154. http:/ / www.propuestaeducativa.flacso.org.ar/tesis.php?id=46\&num $=43$ 
Di Piero, E. (2016). "Justicia, meritocracia e igualitarismo. Procesos de producción y legitimación de desigualdades en escuelas secundarias universitarias en la ciudad de La Plata". Tesis correspondiente al Doctorado en Ciencias Sociales- FLACSO/Argentina.

Di Piero, E. (2017) "Secundarias universitarias en Argentina: políticas de admisión y justicia distributiva". Espacios en Blanco - Serie indagaciones - $\mathrm{N}^{\circ} 28$ - Junio 2017. http://www.scielo.org.ar/scielo.php

Di Piero, E. (2018). "Pasado y presente del nivel secundario: masificación y políticas de admisión". En: Suasnábar, C., Rovelli, L., Di Piero, E. (Coord.) (2018) Análisis de Política Educativa: teorías, enfoques y tendencias recientes en la Argentina, Colección Libros de Cátedra, EDULP, UNLP, disponible en: http://sedici.unlp.edu.ar/handle/10915/68141

Dubet F. (2012). Repensar la justicia social. Contra el mito de la igualdad de oportunidades. Buenos Aires: Siglo XXI.

Dubet, F. (2004). ¿Mutaciones institucionales y/o neoliberalismo? En Tenti Fanfani, E. (org), Gobernabilidad de los sistemas educativos en América Latina. Buenos Aires: IIPE-UNESCO.

Duru-Bellat, M. y Tenret, É. (2009).L'emprise de la méritocratie scolaire: quelle légitimité? Revue française de Sociologie (50) 2, pp. 229- 258.

Elster, J. (1998) Justicia Local, Barcelona: Gedisa.

Fernandez Vavrik, G. (2015) "L'origine comme ressource: la discrimination positive à l'université argentine”. Revista Critique internationale, París, n 70, janvier-mars., p. 159-181.

Funes, J- (2004). "Cómo explicar, cómo analizar la diversidad adolescente. Una propuesta de análisis a partir de los territorios escolares", en Reguillo, Rossana et al. Tiempo de híbridos. Entresiglos. Jóvenes. México- Cataluña, México: SEP/ IMJ/ Secretaria General de Juventud/ Consorci Institut d' Infancia i Món Urba.

Gargarella, R. (1999) Las teorías de la justicia después de Rawls, Buenos Aires: Paidós.

Jay, M. (1999) "Must Justice be blind? The challenge of images to the law", in Douzina, Costas \& Lynda, Nead [comp.] Law and the image. The authority of art and the aesthetics of law, Chicago \& London: University of Chicago Press.

Kessler, G. (2007). Principios de justicia distributiva en Argentina y Brasil. Eficacia global, igualitarismo limitado y resignificación de la jerarquía. En Grimson A. (comp.). Pasiones Nacionales. Política y Cultura en Brasily Argentina. Buenos Aires: Edhasa.

Kessler, G. (2014). Controversias sobre la desigualdad. Argentina, 2003-2013. Fondo de Cultura Económica. Buenos Aires.

Khan, SR. (2011). Privilege: the making of an adolscent elite at St. Paul's School. Princeton: Princeton University Press. 
Mayer, L y Núñez, P. (2017). “Desigualdades en la educación juvenil en América Latina”. Revista Temas, 87-88, julio-diciembre, pp. 12-19

Méndez, A. (2013) El Colegio. La formación de una elite meritocrática en el Nacional de Buenos Aires. Buenos Aires: Sudamericana.

Miller, D. (1996) “Introducción”, en Miller, D. y Walzer, M. [comp.] Pluralismo, justicia e igualdad, Buenos Aires: Fondo de Cultura Económica.

Núñez, P. \& Otero, E. (2018) "Demandas y acciones políticas en la agenda del movimiento estudiantil secundario. El caso de una escuela preuniversitaria de la Ciudad de Buenos Aires" en Beretta, D.; Laredo, F.; Nuñez, P. \& Vommaro, P. (comp.) Politicas de juventudes y participación politica: perspectivas, agendas y ámbitos de militancia Rosario: UNR Editora. Editorial de la Universidad Nacional de Rosario, pp. 29-48.

Núñez, P. \& Litichever, L. (2015) Radiografía de la experiencia escolar. Ser joven (es) en la escuela. Buenos Aires: Ed. Aula Taller.

Otero, E. (2018) "La política estudiantil en movimiento. Un estudio sobre las agrupaciones políticas en una escuela secundaria de la Ciudad de Buenos Aires". Tesis defendida en la Maestría en Ciencias Sociales con Orientación en Educación de FLACSO (Facultad Latinoamericana de Ciencias Sociales- Sede académica Argentina), diciembre.

Perrenoud, P. (1996) La construcción del éxito y del fracaso escolar. Hacia un análisis del éxito, del fracaso y de las desigualdades como realidades construidas por el sistema escolar. Paideia Morata, Madrid.

Pousadela, I. (2007) "Las políticas públicas y las matrices nacionales de Cultura política”, en Grimson, A. (comp.) Pasiones Nacionales. Politica y Cultura en Brasily Argentina. Edhasa: Buenos Aires.

Rawls, J. (1993) [1971] Teoría de la Justicia. Fondo de Cultura Económica: Buenos Aires.

Reygadas, L. (2004) Las redes de la desigualdad. Un enfoque multidimensional. Politica y Cultura (22), 7-25.

Saraví, G. (2015) Juventudes Fragmentadas: Socialización, Clase y Cultura en la Construcción de la Desigualdad. FLACSO, México.

Sen, A. (1996). Capacidades y bienestar. En Nussbaum, M. y Sen, A. (comp), La calidad de vida. México DF: Fondo de Cultura Económica.

Sennett, R. (2003). El respeto. Sobre la dignidad del hombre en un mundo de desigualdad. Barcelona, Anagrama.

SITEAL Atlas de las Desigualdades Educativas Capítulo 2: accesible en http://www.atlas.siteal.iipe.unesco.org/capitulo 2)

Tiramonti, G. y Ziegler, S. (comp.) (2008) La educación de las elites. Aspiraciones, estrategias y oportunidades. Paidós, Buenos Aires. 
Walzer, M. (2004) [1993] Las Esferas de la Justicia. Una defensa del pluralismo y la igualdad, México: Fondo de Cultura Económica.

Ziegler, S. (2011) "Entre la desregulación y el tutelaje: ¿hacia dónde van los cambios en los formatos escolares?”, en G. Tiramonti (Dir.), Variaciones sobre la forma escolar. Limites y posibilidades de la escuela media. Homo Sapiens, Rosario.

Submetido: $11 / 06 / 2019$

Aprovado: 05/11/2019 